\title{
Tympanic membrane temperature as a measure of core temperature
}

\author{
Charmaine Childs, Ruth Harrison, Claire Hodkinson
}

\begin{abstract}
Background-Ear thermometers are becoming popular as a method for measuring deep body (core) temperature.

Aim-To determine the variability of a single user's tympanic membrane (ear) temperature measurements.

Subjects-Forty two, afebrile, healthy children, and 20 febrile children with acute burns.

Results-In afebrile children measurements made in both ears (and within just a few minutes of each other) differed by as much as $0.6^{\circ} \mathrm{C}$. Operator measurement error, $s_{w}$ of three consecutive measurements, in the same ear, was $0.13^{\circ} \mathrm{C}$. In the group of febrile, burned children, core temperature was measured hourly at a number of sites (ear, rectum, axilla, bladder). A peak in core temperature occurred approximately 10-12 hours after the burn. Measurement error was calculated in 14 febrile, burned children with a peak temperature in excess of $38^{\circ} \mathrm{C}$. For the left ear, measurement error was $0.19^{\circ} \mathrm{C}$ and for the right ear, $0.11^{\circ} \mathrm{C}$. In the febrile children agreement between the ears was poor. The limits of agreement were $0.4^{\circ} \mathrm{C}$ to $-0.8^{\circ} \mathrm{C}$. It was not possible to predict the occasions when the temperature differences between the ears would be large or small.

Conclusions-The measurement error of one recording from the next is probably acceptable at about 0.1 to $0.2^{\circ} \mathrm{C}$. To limit the variations in temperature of one ear to the other, measurements should be restricted to one of the ears whenever possible and the same ear used throughout the temperature monitoring period. Nurses and parents should take more than one temperature reading from the same ear whenever possible.

(Arch Dis Child 1999;80:262-266)
\end{abstract}

Keywords: tympanic membrane temperature; measurement error; temperature; burns

Regional Paediatric Burns Unit, Booth Hall Children's Hospital, Charlestown Road, Blackley, Manchester M9 7AA, UK

C Childs

R Harrison

C Hodkinson

Correspondence to: Dr Childs.

Accepted 10 September 1998 probably the most common of all clinical investigations. The aim when taking a measurement is to determine the deep body "core" temperature. Core temperature, described more fully as deep body temperature, is relatively constant despite wide fluctuations in environmental conditions; in man this is close to $37^{\circ} \mathrm{C} .{ }^{1}$ In contrast the "shell" (of skin and superficial tissues) is influenced by environmental temperatures and is seldom constant. When taking a person's temperature it is the temperature of core tissues that one aims to measure, and it can be assessed in a number of ways.

In young children the axilla is a site that is both accessible and safe, but there has been doubt about the accuracy of axilla temperature as a measure of core temperature. ${ }^{3}$ The ear is another site that is becoming popular, and the technique for measurement has improved recently. The first ear thermometers to be developed involved considerable risk to the patient as a thermocouple was inserted and held under slight pressure against the ear drum. ${ }^{4}$ This was a potentially painful procedure and unsuitable for most patients. Insulating the pinna was a further, but necessary, inconvenience but this was later overcome by zero gradient thermometry. ${ }^{5}$ Siting the thermistor in the insulated external auditory canal ensured that the core temperature measurement was unaffected by environmental temperature. The newer ear thermometers use infrared thermometry ${ }^{6}$ to measure the radiant heat emitted from the tympanic membrane ${ }^{8}$ and so dispense with the need to insert thermocouples and thermistors into the ear. This method is attractive as there is no risk of perforation of the ear drum when the probe is introduced. However, doubts have also been expressed about the accuracy of this method..$^{910}$ When measurements are made in both ears differences are often found. The true temperature of the tympanum can be in doubt ${ }^{11}$ especially in patients with ear infections such as otitis media. ${ }^{12}$

This study aimed to determine the measurement error (within observer variability) for repeated measurements of tympanic membrane (ear) temperature and to compare the tympanic temperature measurement with that at other "core" temperature sites. (In healthy children the axilla was the other site.) It is not sufficient to validate the method in healthy children only, therefore febrile children were also studied. Burned children were examined as they usually become febrile during the first 24-36 hours after the burn injury and this fever has been well characterised. ${ }^{13}{ }^{14}$ In burnt patients, the tympanic membrane could be compared with that in the axilla, rectum, and bladder, the last being a particularly good measure of deep body temperature. ${ }^{15}$

\section{Methods}

HEALTHY, AFEBRILE SUBJECTS

Tympanic membrane and axilla temperatures were measured in children with minor skin lesions or healed minor burns attending the plastic surgery and burns aftercare clinic. 
Tympanic temperature measurements were made using the Core Check tympanic thermometer (model 2090; Ivac, Basingstoke, UK) inserted into the auditory canal. Axilla temperature was measured using the Ivac Temp Plus II electronic thermometer (San Diego, California, USA).

After the purpose of the temperature measurement had been explained to the parent and child, outdoor clothing was removed and children were exposed to a constant environmental temperature for between 10 and 20 minutes before the measurements were taken. This should be sufficient to accustom them to their surroundings and eliminate the short lived effects of minor temperature disturbances, although, as discussed by Stoner et al, ${ }^{16}$ it is doubtful if temperature stability can ever be achieved as it is always changing in response to environmental and physiological factors. Ambient temperature (dry bulb) was measured with an electronic weather station (Edale Instruments; Cambridge, UK).

For measurement of tympanic membrane temperature, the pinna was gently pulled backwards and the ear thermometer inserted into the external auditory meatus, turned and directed towards the eye. The probe remained briefly (1-2 seconds) in this position until the machine bleeped to signal a recording. A second measurement was made in the other ear and the routine repeated (that is, first left, first right ear, second left, second right ear) and this protocol was followed strictly. The mean temperatures of the right and left ears were calculated from these measurements. As a comparison between core temperature sites, a single measurement of axilla temperature was made in each child.

We also needed information about measurement error (within observer variability) for axilla temperature measurements. A second group of healthy, afebrile subjects was studied. In this group three consecutive measurements of axilla temperature were made and averaged.

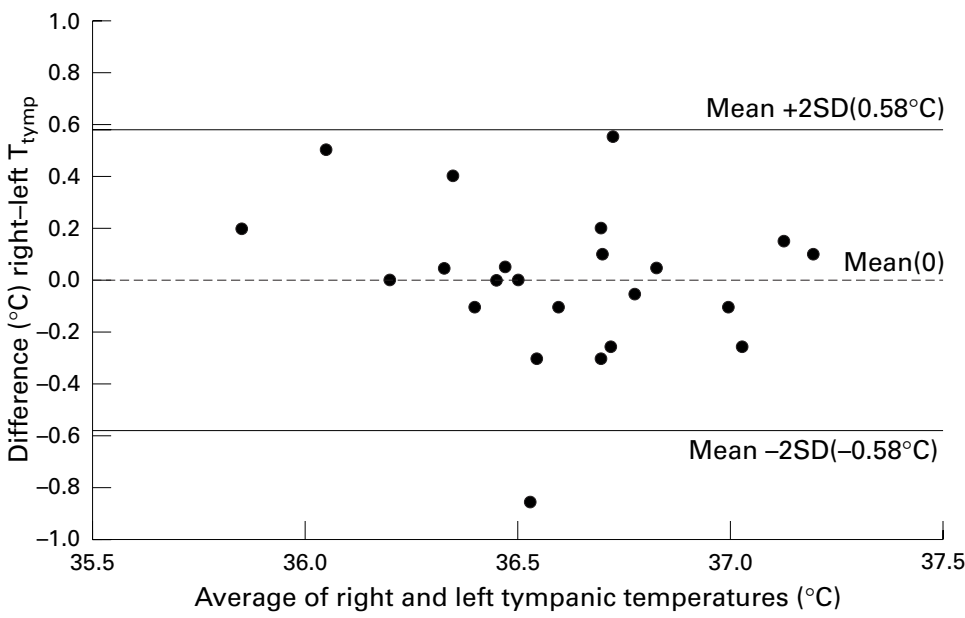

Figure 1 Limits of agreement between mean right and mean left tympanic membrane temperatures in 23 healthy, afebrile children (mean of all children). The figure shows the scatter of mean differences (right - left ear temperature) for each subject plotted against the average of all four ear temperatures. There was perfect agreement between the ear temperatures in just three cases. The upper (mean +2SD) and lower (mean-2SD) limits of agreement for this group were $+0.6^{\circ} \mathrm{C}$ to $-0.6^{\circ} \mathrm{C}$ indicating that the right ear measurement could be as much as $0.6^{\circ} \mathrm{C}$ higher or lower than the left ear measurement.
For comparison a single measurement of tympanic membrane temperature was made in each child.

\section{FEBRILE, BURN PATIENTS}

Monitoring rectal temperature forms a part of the clinical protocol for management of children with burns to $10 \%$ or more of the total body surface area. A thermistor (Component Monitoring System, Model 66S; Hewlett Packard, Berkshire, UK) was placed in the rectum 4-6 cm from the anus where it remained throughout the early postburn period. Every hour rectal temperature was recorded and compared with a single measurement of axilla temperature and the mean of four to six tympanic membrane measurements (two to three measurements per ear depending on the condition of the patient).

In two children, core temperature was also obtained from a thermistor incorporated into a urinary catheter (The Kendall Co, UK Ltd, Basingstoke, UK) placed within the bladder. Comparisons between the temperatures at different sites were made every hour for 12 hours from the time of admission to the burns unit. Ambient conditions were also measured.

ANALYSIS OF DATA

Before measurement error (within observer variability) of repeated ear or axilla temperature measurements can be established, a check must be made to ensure that the individual's standard deviation is unrelated to the mean value (Kendall's rank correlation coefficient)that is, that the variability of the operator's measurements does not increase as the temperature rises (or falls). If the variability of the measurements is independent of the temperature value, measurement error can be calculated for that operator from the within-subject standard deviation of repeated measurements (denoted as $\mathrm{s}_{\mathrm{w}}$ ) as described by Bland and Altman. ${ }^{17}$ For the group of subjects in whom repeated measurements were made the difference between two single measurements in the same ear is expected to be within a range of $+2 \sqrt{2 \times s_{w}}$ to $-2 \sqrt{2 \times s_{w}}$. To show the scatter of differences between right and left tympanic membrane measurements and to establish the upper and lower limits of agreement between the ears (mean +2SD, mean -2SD) the method of Bland and Altman was used. ${ }^{18}$

Statistical analyses were made using SPSS (Chicago, Illinois, USA). Where necessary the statistical test used is given in the text.

\section{Results}

HEALTHY, AFEBRILE CHILDREN

Forty two children were studied at a mean (SD) ambient dry bulb temperature of 23 $(1)^{\circ} \mathrm{C}$. In the first group, 23 children aged 3-15 years (median 11 years) were studied. Four consecutive measurements of tympanic membrane temperature (two in each ear) were made over about three minutes followed by a single measurement of axilla temperature. Each set of ear temperature measurements were normally distributed. The ear temperatures of the 
children were measured by the same operator. The SD of each child's mean right and left tympanic membrane temperature was unrelated to the mean value. The variability of the temperature measurements was shown to be independent of the magnitude of the measurement (Kendall's rank correlation coefficient); therefore, the technique of Bland and Altman ${ }^{17}$ was used to calculate measurement error $\left(\mathrm{s}_{\mathrm{w}}\right)$.

There was no significant difference between mean right and left ear measurements (paired $t$ test) with a mean difference of 0 (fig 1 ). However, the scatter of differences between mean right and left measurements was variable (fig 1) with perfect agreement between mean right and left measurements in three cases only (fig 1). All but one measurement was within two standard deviations (2SD) of the mean. The upper and lower limits of agreement between mean right and mean left tympanic temperatures can be given as: mean difference $+2 \mathrm{SD}$ $(+0.58)$ to mean difference $-2 \mathrm{SD}(-0.58)$. Thus, for the subjects in this study the mean temperature of the left ear could be as much as $0.6^{\circ} \mathrm{C}$ higher to $0.6^{\circ} \mathrm{C}$ lower than the right ear, giving a range of differences of $1.2^{\circ} \mathrm{C}$ (fig 1 ).

The common within-subject SD of the repeated temperature measurements $\left(\mathrm{s}_{\mathrm{w}}\right)$ allows estimation of measurement error and is an average of the variances (the squares of the SD) for each child's measurements. For right and left ear temperatures, $\mathrm{s}_{\mathrm{w}}$ was $0.13^{\circ} \mathrm{C}$. Although the temperatures of the ears differ and the limits of agreement are wide (fig 1), the measurement error of repeated measurements for each ear is acceptable.

For the group of 23 subjects, mean tympanic membrane temperature was compared with a single axilla measurement. There was no significant difference between the two sites: mean tympanic membrane $v$ axilla temperature was $36.6(0.69)^{\circ} \mathrm{C} v 36.5(0.07)^{\circ} \mathrm{C}$ (mean with (SE); paired $t$ test).
In the second group of 19 healthy, afebrile children (aged 8 months to 15 years, median 3 years) three consecutive measurements of axilla temperature were made, the thermometer being withdrawn between each measurement. All first, all second, and all third axilla measurements were normally distributed. The SD of each child's mean axilla measurements was unrelated to the mean (Kendall's rank correlation coefficient). Measurement error $\mathrm{s}_{\mathrm{w}}$ was $0.35^{\circ} \mathrm{C}$.

For comparison, a single ear measurement was made in this same group of children but there were no significant differences in temperature at the two sites: mean axilla $v$ tympanic temperature was $36.2(0.12)^{\circ} \mathrm{C} v$ $36.3(0.14)^{\circ} \mathrm{C}$ (mean with (SE)).

\section{FEBRILE PATIENTS}

Twenty patients aged 0.92 to 13.0 years (median 2.21 years) with total body surface burns of $3-19 \%$ (median $7 \%$ ) nursed at a dry bulb ambient temperature of approximately $30^{\circ} \mathrm{C}$, showed the same characteristic pattern of core temperature as described in previous studies of acutely burned children (fig 2)..$^{13}$

Mean tympanic membrance and axilla temperatures for the patients at the time of admission were within the expected range (mean axilla temperature $36.5^{\circ} \mathrm{C}$; mean tympanic membrane temperature $36.7^{\circ} \mathrm{C}, \mathrm{p}=0.046$, paired $t$ test).

Within a short time (approximately 10-12 hours after the burn) temperature at all core sites rose significantly $(\mathrm{p}<0.0001$, paired $t$ test) from the temperature measured on admission (table 1). For the group of 20 patients, the changes in core temperature were not related to burn size (\% of total body surface area).

The SD of each patient's mean right and left ear temperatures were unrelated to the mean value (Kendall's rank correlation coefficient).

Table 1 Deep body (core) temperature $\left({ }^{\circ} \mathrm{C}\right.$ ) measured in the ear, axilla, rectum, and bladder during the first 15 hours after burns of different severities

\begin{tabular}{|c|c|c|c|c|c|c|c|c|c|c|c|c|c|c|}
\hline \multirow[b]{2}{*}{ Patient } & \multirow{2}{*}{$\begin{array}{l}\text { Age } \\
\text { (years) }\end{array}$} & \multirow{2}{*}{$\begin{array}{l}\text { Burn } \\
(\%)\end{array}$} & \multicolumn{3}{|l|}{ Ear $^{*}$} & \multicolumn{3}{|c|}{ Axilla } & \multicolumn{3}{|c|}{ Rectum } & \multicolumn{3}{|c|}{ Bladder } \\
\hline & & & $O / A$ & Peak & $\Delta$ & $O / A$ & Peak & $\Delta$ & $O / A$ & Peak & $\Delta$ & $O / A$ & Peak & $\Delta$ \\
\hline 1 & 0.92 & 3 & 36.4 & 39.0 & 2.6 & 36 & 37.2 & 1.2 & - & - & - & - & - & - \\
\hline 2 & 8.5 & 3 & 37.1 & 38.4 & 1.3 & 37.2 & 38.6 & 1.4 & - & _ & - & - & _ & - \\
\hline 3 & 1.75 & 3 & 36.5 & 36.6 & 0.1 & 36.5 & 36.6 & 0.1 & - & - & - & - & - & - \\
\hline 4 & 10.0 & 4 & 36.6 & 37.9 & 1.3 & 36.3 & 36.9 & 0.3 & - & - & - & - & - & - \\
\hline 5 & 2.3 & 4 & 36.8 & 37.6 & 0.8 & 35.5 & 37.7 & 2.2 & - & - & - & - & - & - \\
\hline 6 & 1.58 & 5 & 36.5 & 37.3 & 0.8 & 36.6 & 36.6 & 0 & - & - & - & - & - & - \\
\hline 7 & 1.66 & 5 & 35.4 & 39.1 & 3.7 & 35.5 & 39.2 & 3.7 & - & - & - & - & - & - \\
\hline 8 & 7.0 & 5 & 37.1 & 37.5 & 0.4 & 37.1 & 37.3 & 0.2 & - & - & - & - & - & - \\
\hline 9 & 2.08 & 6 & 37.5 & 38.7 & 1.2 & 36.5 & 38.3 & 1.8 & - & - & - & - & - & - \\
\hline 10 & 2.33 & 7 & 37.2 & 38.4 & 1.2 & 36.9 & 38.0 & 1.1 & - & - & - & - & - & _- \\
\hline 11 & 13.0 & 8 & 36.9 & 37.8 & 0.9 & 36.5 & 37.3 & 0.8 & - & - & - & - & - & - \\
\hline 12 & 1.83 & 8 & 36.5 & 38.8 & 2.3 & 36.5 & 38.1 & 1.6 & - & - & - & - & - & - \\
\hline 13 & 2.5 & 9 & 37.1 & 38.1 & 1.0 & 37.6 & 37.5 & 0.1 & - & - & - & - & - & - \\
\hline 14 & 1.25 & 9 & 36.6 & 39.5 & 2.9 & 36.7 & 39.5 & 2.8 & - & - & - & - & - & - \\
\hline 15 & 1.25 & 11 & 37.3 & 39.6 & 2.3 & - & - & - & 37.8 & 39.9 & 2.1 & 38.2 & 39.7 & 1.5 \\
\hline 16 & 3.25 & 13 & 36.9 & 39.1 & 2.2 & 36.6 & 39.2 & 2.6 & 38.1 & 40.2 & 2.1 & - & - & - \\
\hline 17 & 2.83 & 16 & 37.2 & 38.2 & 1.0 & 37.1 & 38.4 & 1.3 & 37.0 & 40.2 & 3.2 & - & - & - \\
\hline 18 & 1.42 & 16 & 37.3 & 39.5 & 2.3 & - & - & - & 37.8 & 40.0 & 2.2 & 37.9 & 39.8 & 1.9 \\
\hline 19 & 1.58 & 16 & 37.1 & 39.4 & 2.3 & _ & _- & _ & 37.2 & 39.6 & 2.4 & - & - & - \\
\hline 20 & 9.0 & 19 & 36.7 & 38.3 & 1.6 & 35.5 & 37.8 & 2.3 & 37.8 & 39.0 & 1.2 & - & - & - \\
\hline
\end{tabular}

All temperatures were measured before administration of paracetamol.

$\star$ Single (first left) tympanic membrane (ear) temperature measurement only.

$\mathrm{O} / \mathrm{A}$, lowest temperature measured at this site during the first few hours after admission (range 2-5.5 hours, median 4 hours after the burn).

Peak, highest temperature measured during the first 15 hours after the burn.

$\Delta$, difference between peak and $\mathrm{O} / \mathrm{A}$. 

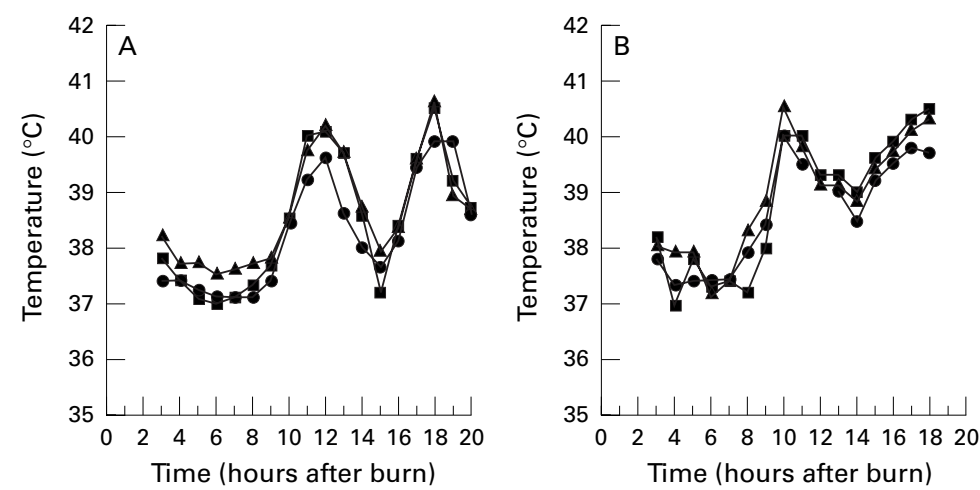

Figure 2 Pattern of core temperature in two burned children. (A) Girl aged 1.25 years with an $11 \%$ scald. (B) Boy aged 1.42 years with a $16 \%$ scald. Rectum (squares), bladder (triangles), and a single tympanic membrane (circles) temperature are shown. The pattern of core temperature at all sites during the early postburn period is consistent with earlier reports showing peak values 10-12 hours after the burn. ${ }^{13} 14$

Measurement error $\left(\mathrm{s}_{\mathrm{w}}\right)$ of repeated ear temperatures (two measurements in each ear) was calculated in 14 burned children whose peak ear temperature 7-13 hours after the burn was in excess of $38^{\circ} \mathrm{C}$. Measurement error $\left(\mathrm{s}_{\mathrm{w}}\right)$ was $0.19^{\circ} \mathrm{C}$ for the left ear and $0.11^{\circ} \mathrm{C}$ for the right ear.

Agreement between the temperature of the two ears was poor. The average temperature difference between mean right and left ear temperatures for the 14 febrile patients was $-0.17^{\circ} \mathrm{C}$ with limits of agreement of $0.4^{\circ} \mathrm{C}$ to $-0.8^{\circ} \mathrm{C}$. In this group of febrile children the temperature differences between right and left ears were of a similar range as in the afebrile children, the range covering $1.2^{\circ} \mathrm{C}$.

\section{Discussion}

It is not difficult to imagine why the tympanic thermometer has such appeal. Looking through the manufacturer's literature many advantages are listed, not least the safety and speed with which a measurement can be made, a great bonus for those who work with children. ${ }^{19}$ Compared with the mercury in glass thermometer (which can take as long as eight minutes for an accurate oral measurement ${ }^{20}$ ), electronic ear thermometers have been welcomed because measurement can be taken in 1-2 seconds. ${ }^{6}$ Over the past few years, infrared ear thermometers have become very popular and some hospital trusts have recommended that ear thermometers replace all previously used electronic thermometers.

Why use the ear to measure core temperature? The answer can be traced to early experimental studies attempting to measure brain temperature at a site close to the temperature regulating centre, the hypothalamus. ${ }^{21}$ The closest one can get, anatomically, to the hypothalamus without surgery is the tympanic membrane, and access to this is via the external auditory canal. We know now that other areas of the brain are involved in thermoregulation ${ }^{22}$ so estimation of the hypothalamus may not be as significant as once thought. Nevertheless, the tympanic membrane has a good blood supply (from the deep auricular branch of the internal maxillary artery, the stylomastoid branch of the posterior auricular artery, and the tympanic branch of the maxillary artery ${ }^{23}$ ) so the temperature at the tympanum is probably about the best one can get as an indirect measure of brain temperature.

Modern ear thermometers are easy to use and are popular, but not all nurses and clinicians are happy using them because the measurements are often unbelievable. Our initial observations of unusually low ear temperatures (about $34^{\circ} \mathrm{C}$ ) in children coming in from the cold bears this out. Using ear thermometers when the ears are cold may therefore give unreliable results, which could have disastrous clinical consequences.

What is the explanation for these erroneous measurements? First, the probe, once inserted into the ear must "see" the tympanic membrane. ${ }^{24}$ If it does not, the infrared radiation emitted from it will not be picked up so the final measurement is likely to be different from the true tympanic membrane temperature. As the ear thermometers in use today do not insulate the ear, it is unlikely that the temperature of the external ear canal will be in equilibrium with the tympanic membrane. ${ }^{6}$ The ear canal is shorter in children than in adults, hence it is prone to cooling (or heating) from the environment, and this will ultimately affect the temperature lower down the ear canal. To help position the probe so that it focuses on to the membrane, the normally tortuous ear canal (of older children and adults) can be straightened by pulling or tugging the pinna, and directing the probe into the ear and rotating it towards the eye..$^{24}$ If one cannot be certain of the position of the probe once it is in the ear, one cannot exclude the possibility that the probe is focused on an unidentified area of skin of the external auditory canal wall.

Some authors ${ }^{25}$ appear to be confident of the accuracy of ear thermometers, reporting good agreement between the temperatures of the ears. We have shown that, in a constant and comfortable environment (dry bulb ambient temperature $23^{\circ} \mathrm{C}$ for partially clothed control subjects and $30^{\circ} \mathrm{C}$ for febrile, acutely burned children), there are notable differences between the temperatures of the ears in the children. We found that in healthy, afebrile children the temperature of one ear can, in the worst case, differ from the other ear by more than half a degree $\left(0.6^{\circ} \mathrm{C}\right)$ when measured over a period of a minute or so. In the febrile child, there are times when the difference between the ears is minimal, but equally there are times when the temperature of one ear can differ from the other. The range of differences are the same in the febrile patients as they are in the afebrile children $\left(1.2^{\circ} \mathrm{C}\right)$. We are not clear whether the difference in one ear compared to the other is a true difference or an artefact of the operator's technique. We have been unable to find any evidence to support the notion that there is a physiological difference in temperature between the ears, but as the differences are unpredictable, one rather feels that it is the measurement technique that is responsible for the variations in measurement that we have seen. 
What about the measurement error for repeated readings in the same ear? In the afebrile children, axilla and ear temperatures are not significantly different, but there is a tendency for a bigger measurement error when temperatures are taken in the axilla $\left(\mathrm{s}_{\mathrm{w}}\right.$ for the axilla, $0.35^{\circ} \mathrm{C}$; for the ear $0.13^{\circ} \mathrm{C}$ ). Failure to reposition the thermometer onto the same site in the ear is most likely to be the cause of operator measurement error.

Some concern has been raised about the inability of ear thermometers to detect a rise in core temperature caused by fever ${ }^{26}$ or exercise, ${ }^{27}$ but we have not found this to be a problem. The characteristic biphasic fever pattern $^{13}{ }^{14}$ was apparent using all core sites, and the changes in the febrile patients occurred at more or less the same time (fig 2). Despite the claims that ear temperature represents hypothalamic temperature and therefore the true core temperature, we are not convinced that ear temperature is any more of a gold standard for core temperature measurements than-for example, rectal temperature. One of the difficulties in attempting to measure core temperature is that the temperature of different organs vary, albeit in a small way. ${ }^{28} 29$

\section{CONCLUSIONS}

In children, the potential benefits of being able to measure deep body temperature quickly and easily without causing distress are obvious. The ear thermometer appears to be the ideal instrument to do this and is suitable for use in hospital as well as in the home. Ear thermometers can now be bought by the public so one can expect that they will become widely used by parents of young children. We have shown that the ears are not always at the same temperature. At least two measurements should be made in the same ear. Repeating the measurement does not always guarantee that the value will be the same and one can be forgiven for wondering which, if any, of the measurements is the true measure of tympanic membrane temperature.

To limit the variations in temperature of one ear to the other, measurements should be restricted to one of the ears whenever possible and this ear used throughout the monitoring period. Two measurements from the same ear is probably a realistic recommendation for nurses to incorporate into clinical practice. It seems that the measurement error of one recording from the next is probably acceptable at about 0.1 to $0.2^{\circ} \mathrm{C}$. It is the difference in the temperatures between the ears that should be borne in mind when using ear thermometers.

One recommendation to improve the technique of ear temperature measurement would be to design an instrument that allows the operator to visualise the tympanic membrane while detecting the infrared radiation emitted from it.
Our thanks to Mr Kevin Ryan and the nursing staff of the Burns Unit and to Sister Gill McLaren and Jean Simpson of the Frank Robinson Burns Aftercare Clinic for their help and cooperation with the study. Many thanks to Professors H B Stoner and R A Little and to Dr Valerie Hillier for their help with the preparation of the manuscript.

1 Edholm OG. Man - hot and cold. London: Edward Arnold Ltd, 1978:1-12

2 Stainer MW, Mount LE, Bligh J. Energy balance and temperature regulation. Cambridge: Cambridge University Press, 1984.

3 Haddock BJ, Merrow DL, Swanson MS. The falling grace of axillary temperature Pediatric Nurse 1996;22:121-5.

4 Benzinger TH. A newly discovered sensory organ in the brain precisely measures the body temperature and trips heat-dissipating mechanisms that maintain the temperature within a fraction of one degree. Scientific American 1961;203:134-47.

5 Keatinge WR, Sloan REG. Measurement of deep body temperature from external auditory canal with servo-controlled heating around ear. F Physiol (Lond) 1973;234:8-9.

6 Edge G, Morgan M. The Genius infrared tympanic thermometer. Anaesthesia 1993;48:604-7.

7 Fraden J, Lackey RP. Estimation of body sites temperatures from tympanic measurements. Clin Paediatr 1991; 30(suppl):65-70.

8 Clarke RP, Edholm OG. Man and his thermal environment. London: Edward Arnold, 1985:36.

9 Hooker E. Use of tympanic thermometers to screen for fever in patients in a pediatric emergency department. South Med f 1993;86:855-8.

10 Brogan P, Childs C, Phillips BM, Moulton C. Evaluation of tympanic thermometer in children. Lancet 1993;342: 1364-5.

11 Romanovsky AA, Quint PA, Benikova Y, Kiesow LA. A difference of five degrees $C$ between ear and rectal temperatures in a febrile patient. Am $\mathcal{F}$ Emerg Med 1997; 15:383-5.

12 Kelly B, Alexander D. Effect of otitis media on infrared tympanic thermometry. Clin Pediatr 1991;30(suppl):46-9.

13 Childs C. Fever in burned children. Burns 1988;14:1-6

14 Childs C, Little RA. Acute changes in oxygen consumption and body temperature after burn injury. Arch Dis Child $1994 ; 71: 31-4$

15 Fox RH, Fry AJ, Woodward PM, Collins JC. Diagnosis of accidental hypothermia of the elderly. Lancet 1971:i:424.

16 Stoner HB, Barker P, Riding GSG, Hazelhurst DE, Taylor L, Marcuson RW. Relationship between skin temperature and perfusion in the arm and leg. Clin Physiol 1991;11:2740 .

17 Bland JM, Altman DG. Measurement error. BMf 1996;312: 1654.

18 Bland JM, Altman DG. Statistical methods for assessing agreement between two methods of clinical measurement. BMF 1986;i:307-10.

19 Terndrup TE, Milewski A. The performance of two tympanic thermometers in a pediatric emergency department. Clin Pediatr 1991;30(suppl):18-23.

20 Nichols GA, Kucha DH. Taking adult temperatures: oral measurements. Am f Nursing 1972;72:1091-3.

21 Benzinger TH. Heat regulation: homoeostasis of central temperature in man. Physiol Rev 1969;49:671-748.

22 Milton NGN. Effect of peripheral corticotrophin releasing factor on febrile responses In: Milton AS, ed. Temperature regulation. Recent physiological and pharmacological advances. Basel: Birkhauser Verlag, 1994:1-10.

23 Gray H. The arteries. In: Pick TP, Howden R, eds. Anatomy, descriptive and surgical. New York: Bounty Books, 1977: 496.

24 Pransky SM. The impact of technique and conditions of the tympanic membrane upon infrared thermometry. Clin tympanic membrane upon
Pediatr 1991;30(suppl):50-2

25 Shenep JL, Adair JR, Hughes WT, et al. Infrared, thermistor, and glass-mercury thermometry for measurement of body temperature in children with cancer. Clin Pediatr 1991; 30(suppl):36-41.

26 Rhoads FA, Grandner J. Assessment of an aural infrared sensor for body temperature measurement in children. Clin Pediatr 1990;29:112-15.

27 Yeo S. Scarbough M. Exercise-induced hyperthermia may prevent accurate core temperature measurement by prevent accurate core temperature measurement by tympanic

28 Graf W. Patterns of human liver temperature. Acta Physiol Scand 1959;46(suppl):160.

29 Grayson J, Kuehn LA. Heat transfer and heat loss. In: Lomax P, Schonbaum E, eds. Body temperature regulation, drug effects and therapeutic implications. New York: Marcel Dekker, 1979:71-87. 